Strategic Directions and Newer Dilemmas for Teacher-Librarians and School Library Resource Centres

International Association of School Librarianship. Selected Papers from the ... Annual Conference; 2002;

\title{
Strategic Directions and Newer Dilemmas for Teacher-Librarians and School Library Resource Centres
}

\author{
Ken Haycock \\ Professor, School of Library, Archival and Information Studies \\ The University of British Columbia \\ 854C-1956 Main Mall, \\ Vancouver, British Columbia V6T 1Z1, \\ Canada \\ ken.haycock@ubc.ca
}

\begin{abstract}
Once a leader in the provision of effective school library services, the Vancouver (British Columbia, Canada) School Board has seen its intellectual and material assets diminish with growing confusion about the role of the teacher-librarian, particularly with regard to information technologies. The investigator reviewed the current status of school library resource centres, including staffing, resources and use, to identify "revenue-neutral" improvements based on research evidence and best practice. In the course of the review several dilemmas emerged that challenged conventional wisdom regarding the delivery of school library services; these dilemmas are the focus of this paper.
\end{abstract}

\section{Introduction}

The Vancouver (British Columbia, Canada) School Board has been a leader in resource-based learning through teacher-librarians and school library resource centres for almost thirty years. The "service" is based on collaborative program planning and team teaching between teacher and teacher-librarian to integrate "information literacy" with the classroom program, with the support of the principal and district staff. Studies by the Board itself, and by others, indicated that this model enhanced student achievement, curriculum implementation and the development of collaborative work environments in schools.

During the past ten years, however, several changes have resulted in stress on this program and the various partners in its maintenance. Budget reductions by the Province of British Columbia Ministry of Education, the funding agency, have resulted in (a) reduction of the central district staff in teacher-librarianship that provided leadership, staff development and training for district curriculum consultants, school principals, teacher-librarians and teachers, (b) elimination of technical and clerical support staff for teacher-librarians in both elementary and secondary schools; and (c) funds for library/learning resources being dramatically reduced. The advent of information technology has also confused roles and responsibilities in the district and school, and resulted in limited resources being redirected to separate technology equipment and staff.

Further, the provincial government legislated provincial bargaining for teachers, meaning that the teachers' union and the employers bargained directly and uniformly for working and learning conditions across the province, a right formerly held by locally-elected school boards and local unions. After three years the two parties could not reach agreement, 
and the provincial government met with the teachers' union and negotiated an "agreement in committee", which resulted in minimum staffing across the province for teacher-librarians of one full-time professional equivalent for every seven hundred students. In the case of Vancouver, this resulted in a reduction or reallocation of some teacher-librarian time for at least part of each day/week to the provision of preparation or relief time for classroom teachers for the first time in thirty years; this was the only way the Board was able to maintain its teacher-librarian staffing in a period of financial cutbacks. Further stress has grown from the move from prescribed provincial curriculum to integrated resource packages placing more responsibility on the school/district for the selection of resources to meet intended learning outcomes. The reduced appeal of the resulting role of the teacher-librarian led to teachers without specialized qualifications being assigned as "teacher-librarian", again for the first time in thirty years.

In order to remain a leader in an program area that promotes student achievement and flexibility in program delivery, the Vancouver School Board identified a need to review the role and responsibilities of teacher-librarians and school library resource centres within the context of existing budget allocations and contractual obligations with teachers and other unions.

\section{Goals and Objectives}

Within the context of current expenditures, contractual obligations, funding issues and appropriate rights and responsibilities of stakeholder groups, this project (Haycock, 2001) reviewed the current status of school library resource centres in the Vancouver school system, including staffing, resources and use, to identify potential improvements based on research evidence and best practice.

The specific research objectives were to clarify the role and responsibilities of the teacher-librarian, to review resource selection and management, to specify coordinated approaches to information technology resources and use, to articulate roles and responsibilities in program development and delivery, to identify mutual roles, expectations and responsibilities with other agencies, specifically the Vancouver Public Library and to identify essential elements of an ongoing professional development plan for teacherlibrarians.

Documents analyzed included Board policies, accreditation recommendations and annual reports; data was collected from a stratified random sample of 50 of 110 schools. More than 150 individuals participated in review sessions.

\section{Research Review}

The research evidence makes it clear that teacher-librarians and school resource centres have a positive impact on student achievement, on motivation and ability to read and on the teaching and learning climate in the school (Haycock, 1996). These effects are achieved with qualified teacher-librarians who collaborate with classroom colleagues to integrate those skills and strategies that enable students to access and use information effectively. The resulting units of study are team taught by the teacher and teacher-librarian in flexibly scheduled resource centres. Support staff frees the teacher-librarian to plan and teach with colleagues. 
The mere presence of staff, facility and resources are not sufficient in and of themselves to bring substantial gains, however, although there is evidence for improvement in achievement even at this level of program development.

Quality programs require a stated aim for the library program, a definition of the role of the qualified teacher-librarian as well as the other partners-province, district, administrators, teachers, a priority on collaborative program planning and team teaching between the teacher-librarian and classroom colleagues, a systematic approach to teaching the information process based on a school-based continuum of information skills and strategies, flexible scheduling of classes and groups after planning, and appropriate and effective program and personnel evaluation by administrators. A program such as this requires administrative leadership and support and effective staff development.

Studies indicate that the development of student competence in information skills is most effective when integrated with classroom instruction through collaborative program planning and team teaching by two equal teaching partners-the classroom teacher and teacher-librarian-in a flexibly scheduled resource centre. The teacher-librarian plays important roles as information and resource specialist, teacher and instructional planner.

The most significant change in roles occurs when the school moves to flexible scheduling and curriculum-integrated instruction, and greater curriculum involvement by the teacher-librarian occurs when flexible scheduling is combined with team planning. Increased interested in books and more enjoyment in reading is also more apparent with reading integration throughout the curriculum, and flexible scheduling. Even student attitudes toward the resource centre and reading are more positive in flexibly scheduled programs.

Students taught through collaborative program planning and teaching have a better understanding of effective use of the library resource centre and achieve significantly better academic scores for both content and skills/strategies.

Studies in Colorado (USA) have been replicated in Alaska, Pennsylvania and Texas, with similar results. Teacher-librarians who are most effective, that is have a positive impact on student achievement, collaborate with colleagues in flexibly scheduled programs and provide leadership in the effective use of resources, including information technologies.

Stephen Krashen, in his review of research on reading and schooling, found that more reading is done where there is a school library and a teacher-librarian. Children also read more where they live close to a public library. A print-rich environment, including larger library collections, and a good reading environment, including comfort and quiet, affect reading, literacy and test scores.

\section{Historical Development}

A review of the historical development of Vancouver's school library resource centres over eight years revealed several common elements:

$>$ the role of the Ministry of Education in articulating the role of the teacherlibrarian and library resource centre and providing resource documents and targeted financial support for school libraries;

$>$ the leadership role of the Vancouver School Board in approving policies on the purpose of the program, the role of the teacher-librarian, the selection of learning 
resources, the inclusion of research and study skills in foundation curricula, and the provision of district support and leadership staff, with a cyclical redevelopment of facilities, equipment and collections;

$>$ the district's central approach to resource management with standardized procedures, access and security, and the development of district collections where of greatest economic benefit;

$>$ the active engagement and support of school administrators and teachers;

$>$ the high standards expected of teacher-librarians with minimum professional qualifications and essential in-service education to support expectations;

$>$ the emphasis on collaboration with classroom teachers in developing and implementing integrated programs of use and selecting resources to support those programs;

$>$ the identification of flexible schedules as a goal and movement over time to create these at the secondary and then elementary levels, moving teacher-librarians from providing preparation relief for classroom colleagues;

$>$ the close relationship with the Vancouver Public Library in developing reading and literacy among young people.

In the past fifteen years the Board has faced increased stresses on its financial resources and flexibility to meet local needs and priorities through loss of its right to raise school funds through taxation, reduced funding allocations and provincial bargaining with employee groups. The result for school resource centres has been reductions in professional time at the elementary school level, together with the use of the teacher-librarian to provide preparation time for teachers (a practice eliminated by administrative direction in 1978), elimination of all clerical assistance, and budget reductions for library resources of more than $80 \%$. Private school funding for library resources in greater Vancouver is now typically five times greater than the Vancouver School Board. School raised funds, for example through parent fundraising, now equals the Board allocation at the elementary level and is approximately half at the secondary level. Schools in each area of the city raise funds and make use of adult and student volunteers.

In spite of these reductions and constraints, teachers, administrators, teacher-librarians and parents point to common strengths across the system: committed and qualified staff; supportive administrators and teachers; a focus on collaboration and literacy; linkages between all types of print, video and electronic resources for research and reading for pleasure. Parents note that this is one area of the school for which there is unanimous support for community fundraising.

\section{Strategic Directions}

Six strategic directions with recommendations were proposed based on the study; in summary, the school district should:

(1) approve a role statement for the teacher-librarian outlining both professional and personal competencies; require minimum qualifications for the position; implement written evaluation measures and processes based on the role description and school priorities and initiate a recruitment plan;

(2) identify essential elements of an ongoing professional development plan for teacher-librarians; enable principals and teacher-librarians to develop professional growth 
plans to ensure that the teacher-librarian can meet the stated expectations or move to a classroom position in the system; establish priorities for professional development, including a trainer of trainer model to provide leadership in the selection and use of learning and information technologies in all forms and formats;

(3) review resource selection and management; improve print and audio-visual resources through targeted funding when possible; improve electronic resources through a district approach to identifying appropriate Internet sites; review equipment and facilities; increase clerical and technical support through clarification of roles and responsibilities for technology; encourage the use of adult and student volunteers; improve access to facilities and resources through distinction between using the resource centre and the teacher-librarian, with the school assuming shared responsibility for the facility and access to resources;

(4) specify coordinated approaches to information technology resources and use; make the district's Learning and Information Technologies division-encompassing books, textbooks, videos, electronic resources; equipment and infrastructure-a model for the resource centre, a hybrid approach to the selection, management and use of learning resources to enable greater efficiencies and effectiveness; ensure that teacher leaders for resource services in secondary schools similarly encompass all learning resources at the school level; provide a common graphic user interface for all elementary school students with gateways to appropriate search engines and full-text databases;

(5) articulate roles and responsibilities-the province provides overall direction and funding; the school district provides vision, leadership and training in collaborative planning and teaching, developing an information continuum/process, support for the integration of skills and strategies and flexible scheduling, and ongoing assessment and evaluation; provides consultative and technical services and support for resource management; the principal fosters a climate for collaboration, ensures competent personnel and access to the facility and resources in conjunction with all staff; the teacher needs to collaborate with the teacher-librarian for the best use of preparation periods as well as integrated programs; parents and students are also partners as major funders, supporters and users of the service;

(6) identify mutual roles, expectations and responsibilities with the Vancouver Public Library; each agency selects and manages resources for a common client group and develops literacy programs to encourage best use of those resources; pursue collaborative projects, from homework centres to family literacy programs to a centre for research and professional resources; each student should have a library card and a visit to the public library by the end of the fourth grade.

\section{Professional Dilemmas \\ Role of the Teacher-librarian}

The Vancouver School Board had a long history of full-time qualified teacherlibrarians in elementary schools with more than 300 students; over time this had been increased to 350 students. With provincial bargaining and funding based on one teacherlibrarian for 700 students it was likely that staffing would be reduced by half. In a move to "protect" teacher-librarians, the Board's senior management team decreed that school principals must use teacher-librarians to provide coverage for classroom teachers for at least part of each week to maintain them in full-time positions. This was an unpopular decision. Some principals preferred to use the coverage to enable them to continue art, music and/or 
physical education programs which were eliminated in budget reductions. Teacher-librarians were angry that their time was being "misused" to provide relief or preparation periods for their colleagues. In interviews, the one issue continually identified by teacher-librarians as the impediment to the development of an exemplary program was that up to half of their time was being used for these scheduled classes.

The dilemma here, in a fixed funding situation, is whether to recommend that (a) teacher-librarians have a flexible schedule only, with reduced time, ensuring that the time allocated is used effectively and there is no confusion about the time available for collaboration and team teaching or (b) teacher-librarians be full-time, even if that meant that some of their time needed to be spent teaching scheduled classes, in order to ensure maximum time in the library resource centre and maximum attention to the Board's investment in facilities and resources.

The recommendation eventually made suggested that no more than one-third of a teacher-librarian's time should be allocated to scheduled classes and that this should be at a time when limited school support staff might supervise to enable multiple activities to be undertaken at the same time. Further, the time spent teaching scheduled classes was not to be recorded as teacher-librarian time but as preparation coverage time so as not to confuse the time allocated as teacher-librarian and not to confuse the role expectations for the teacherlibrarian.

\section{The Role of the Teacher-librarian and Information Technology}

Like school system around the world, the Vancouver School Board recognized a need to provide appropriate computer hardware and software in a time of financial restraint. Similarly, the linkage between library resource centres and information technology was not made and was not promoted actively and uniformly by teacher-librarians. Some teacherlibrarians were leaders in this integration and some had no interest in assuming additional responsibility in a new area for them. Decisions were made on individual interest rather than role clarification. Indeed, at the secondary school level entire departments were developed around technology while the teacher-librarian in charge of the secondary school library resource centre had the title "Head of Resource Services".

The dilemma for the investigator was to recommend changes to clarify roles and responsibilities that recognized ability to deliver quality programs and services. Many recommendations were made for improvements in the central office and at the school level, including training teacher-librarians for positions of leadership in learning and information technologies. However, should teacher-librarians assume more and more responsibilities while their support staff and time is being eroded? Conversely, will they ever get more time and attention if they avoid areas of high priority in the system, such as information technology? It was recommended that teacher-librarians, technology staff and all resources be integrated in secondary schools under the Head of Resource Services; this was acceptable to neither the teacher-librarians nor the Board management.

\section{School Priorities and Support}

Each school in Vancouver has some flexibility in its staffing and operations beyond the labour contracts and allocated resources. Each school receives an allocation of teacher- 
librarian time and a budget for library resources; beyond that, they are free to allocate resources themselves, limited as those resources may be. Some examples follow.

In a study subset of 39 (of more than 90) elementary schools, allocation of paid clerical assistance ranged from no assistance at all (28 schools) to 12 hours per week (one school). Adult volunteer time ranged from 45 hours per week (one school) to no adult volunteers (seven schools). Student volunteer time ranged from 35 hours per week (one school) to no student volunteers (nine schools).

Of the sample, the average enrolment was 372 students with 1.6 hours of paid clerical assistance, 6.9 hours of adult volunteer help per week, and 6.7 hours of student assistance. The school raised an additional $\$ 3,095.54$ for the resource centre, or $\$ 8.94$ per student. Of the sample, the median enrolment was 375 students with no paid clerical assistance, 4.0 hours of adult volunteer help per week, and 5.0 hours of student assistance; the school raised an additional $\$ 2,300.00$ or $\$ 6.47$ per student.

\section{Note that most schools raise as much money for library resources as what the school district allocates.}

Determining the best situation depends on relative value of paid assistance, adult and student volunteer assistance and school allocated funds for resources. One best "resourced" school, from school-set priorities, enjoyed 75 hours of volunteer assistance and an additional $\$ 12$ per student for library resources. Another best "resourced" school, from school-set priorities, enjoyed 10 hours of paid clerical assistance, 11 hours of adult volunteer time and an additional $\$ 39$ per student for library resources.

The worst "resourced" school from school-set priorities, "enjoyed" two hours of student assistance and $\$ 1.50$ per student for library resources.

There were no differences across the city in the allocation of paid clerical assistance by school administrators; in other words, socio-economic area had no bearing on this decision. Similarly, and somewhat surprisingly, schools in each area seem capable of recruiting and making effective use of adult and student volunteers. Each school has equal access to student volunteers but greater use is made in one area of the city, suggesting that use is dependent on an attitude toward volunteers generally or a school culture more welcoming of volunteers. Schools in each area of the city also demonstrated the ability to raise funds for library resources.

The situation in secondary schools is similar, examining in greater detail a sample of 11 (of 18) secondary schools for school-based allocations of staffing and funding. Unlike elementary schools, no school provided any paid clerical assistance after all library clerical help was eliminated. (There were union jurisdictional issues here.) Adult volunteer time ranged from 5 hours per week (one school) to no adult volunteers (six schools). Student volunteer time ranged from 80 hours per week (one school) to three hours per week of volunteers (one school).

Of the sample, the average enrolment was 1391 students with no paid clerical assistance, 1.5 hours of adult volunteer help, and 41.4 hours of student assistance; the school raised an additional $\$ 8,513.64$ for the resource centre, or $\$ 5.30$ per student. Of the sample, the median enrolment was 1364 with no paid clerical assistance, no adult volunteer help, and 
40.0 hours of student assistance; the school raised an additional $\$ 3,000.00$ or $\$ .95$ per student.

Determining the best situation depends on relative value of paid assistance, adult and student volunteer assistance and school allocated funds for resources. One best "resourced" school, from school-set priorities, enjoyed 4 hours of adult volunteer assistance, 30 hours of student assistance and an additional $\$ 20.30$ per student for library resources. Another best "resourced" school, from school-set priorities, enjoyed no adult volunteer assistance but 60 hours of student assistance and an additional $\$ 10.96$ per student for library resources.

The worst "resourced" school from school-set priorities, "enjoyed" four hours of adult volunteer assistance, no student assistance and no additional funds for library resources. This is a school in the highest socio-economic area of the city.

In essence, then, regardless of socio-economic area, there are no differences in the allocation of paid clerical assistance by school administrators. Schools in each area seem capable of recruiting and making effective use of adult volunteers. Schools in each area seem capable of recruiting and making effective use of student volunteers. Likewise, ability to raise and allocate funds to library resources appears to be more dependent on school priorities and initiatives than geographic area.

The dilemma here centres on the attitude of the school toward allocation of clerical staff and additional resources to the library resource centre; some teacher-librarians refused to accept additional funds on principle, stating that they should not have to raise additional monies from parents. Similarly, it appears that the teacher-librarian's attitude toward volunteers, whether adults or students, is important in determining whether they will be used and to what extent. Should one's ability to raise funds or work with parents to raise funds, and to engage adult and student volunteers in the library enterprise, be a component of the teacher-librarian's role and a criterion for assessing a teacher-librarian's performance? Certainly every referral to an exemplary library resource centre included extensive use of volunteers and funds seemed to follow.

\section{The District's Role}

The role of the district in developing library resource centres is clear and the Vancouver School Board has played a leadership role in articulating roles and responsibilities, approving policies on qualifications, the selection of materials and standards, and providing district leadership and support services. However, the district has moved from a district-led program with school supervision to a school-based program with limited district support.

The budget for library resources allocated by the district has deteriorated by more than $80 \%$ in twenty years, to CDN $\$ 7$ at the elementary school level per student and CDN $\$ 12$ per student at the secondary school level per student. At the same time, parent and school-raised funds allocated almost CDN $\$ 9$ at the elementary school level per student (more than the district) and more than CDN \$6 per student at the secondary school level per student.

The district allocation of funds is the "official" allocation yet it represents approximately half of the total budget. The dilemma here is that the district bears 
responsibility, together with its funder, to provide adequate support for library resources. The district has never acknowledged the role of parents and schools in supporting library resource centres to the extent that they do. On the one hand, the existing model of schools supplementing district allocations of funds acknowledges both this policy and the economic and political reality. On the other hand, funds would be expended much more judiciously and usefully if the district and schools acknowledged the current reality and the district centralized its allocation and targeted it to specific district-wide initiatives such as database site licences and support for new curricular initiatives. The schools could then allocate their resources to more local needs. Although a better use of funds, this simple change "institutionalizes" school-raised funds in a way that no one appears to want, even though it has been common practice in the district since its inception almost one hundred years ago. Schools are spending inordinate funds on site licences due to this lack of coordination and decentralization of funds.

\section{The Parents' Attitude}

Throughout the interviews with individual parents and representatives of parent advisory councils for schools and with the executive committee of the district parents' advisory council, the support of parents was "absolutely unbelievable". Parents consistently named school libraries, including teacher-librarians and resources, as among their highest priorities for increased funding. One could not ask for a more supportive, active, vocal or effective group to advocate for these programs.

The dilemma rests with the attitude of parents. The parents are enormously supportive of school library resource centres; indeed, in the words of one parent leader: "The school library is the only area of the school where there is never any argument or debate about raising funds. For every other area there is always a difference of opinion about whether it should be a high priority. This is never the case with school libraries. The teacher-librarians enjoy widespread parent support." However, parents raise funds only for areas that they believe are not essential; for example, parents will not raise funds for textbooks or for paid staffing as they believe that these should be provided by government.

Herein lies the dilemma. Teacher-librarians have garnered support from parents to the extent that they are the highest priority of the "non-essential" areas. Of course, this is not the way it was expressed to the researcher and some would dispute the conclusion. Nevertheless, is it better to increase one's priority to become "essential" and thus not able to access funds, or to be the highest of the non-essential areas and enjoy CDN $\$ 375,000$ a year in schoolraised funds?

\section{Policy and Practice}

On the face of it, the provincial government's Ministry of Education acknowledges the research base and "best practice" in teacher-librarianship through references in its curriculum documents such as:

Developing independent learners:

"... students are scheduled... according to program needs..."-page 28

"...students participate...through cooperatively planned and taught units... This cannot occur if the timetable...provide(s)... a "library period" designed to give the classroom teacher a "spare" or preparation period." - page 28 
"The school district...develops policies on resource-based learning, including a flexible scheduling statement."--page 20

\section{Literature connections:}

"Rather than scheduling classes into the library for the same period every week, the teacher-librarian and classroom teachers should plan together to serve the instructional needs of students. Flexible scheduling...-page 26

\section{Language Arts/English Primary-Graduation Position Statements: \\ "Inherent... is the understanding that the library resource centre will be scheduled flexibly..."-page 24}

On the other hand, new funding formulas and agreements with teacher unions anticipate that teacher-librarians will cover preparation periods for classroom teachers and teach scheduled classes at least some of the time.

It is a dilemma for teacher-librarians to confront the gap between policy and practice. Although this is experienced every day as the curriculum written is not the curriculum delivered, it is nevertheless disconcerting to realize that what government says is not necessarily what government does. Advocacy efforts by teacher-librarians will need to acknowledge that government documents often reflect best practice but that government funding often reflects political realities or just plain ignorance. This needs to be understood when seeking support for the implementation of best practice in schools. The dilemma is to find means to work with government and school district agencies in constructive, collaborative ways to integrate "best practice" with actual practice. Of course, this gap is not unique to government; it is also common among school boards and schools. This need for advocacy, that is, developing support and understanding incrementally over time, will require a planned, deliberate and sustained approach, over time, and will be a long and arduous process but must be seen as an integral part of education for teacher-librarians and of the teacher-librarian's work day.

\section{Conclusion}

The purpose of this study was to examine the current status of school library resource centres in the Vancouver (British Columbia, Canada) school system, including staffing, resources and use, and to identify "revenue-neutral" improvements based on research evidence and best practice within the context of current expenditures, contractual obligations, funding issues and appropriate rights and responsibilities of stakeholder groups.

As a result of the study, several dilemmas were identified in which "best practice" was challenged by political realities, that is to say, best practice was possible but perhaps not best in the given situation. These dilemmas centred around the role of the teacher-librarian and its relationship to information technologies, around scheduling and whether more time or greater freedom with more limited time was preferable, around the relationship between attitude and support from volunteers, around the role of the district and school in funding, around parent's perceptions of the library as the "best" after the basics and of the lack of congruence between government pronouncements and government funding. 
There is no one right answer to these dilemmas but they warrant consideration and debate as the reality is that best may not always be best, depending on personal preferences, organizational priorities and community perceptions.

\section{References}

Haycock, K. (2001. October). Reconceptualization and reconfiguration of expectations and service delivery models: A review of the role of the teacher-librarian and school library resource centre in School District \#39 (Vancouver). Research report for the Vancouver (British Columbia) School Board. $256 \mathrm{pp}$.

Haycock, K. (1996). Research in teacher-librarianship and the institutionalization of change. In L. A. Clyde (Ed.). Sustaining the vision: A collection of articles and papers on research in school librarianship (pp. 13-22). Castle Rock, CO: Hi Willow Research and Publishing. 